\title{
Influência da interação fósforo disponível $\times$ fitase da dieta sobre o desempenho, os níveis plasmáticos de fósforo e os parâmetros ósseos de poedeiras comerciais
}

\author{
1 DAP/UFPB/Campus III, CEP: 58.220-000 - Bananeiras, PB. Bolsista do CNPq. \\ 2 Programa de Pós-Graduação em Zootecnia/UFPB - Areia, PB. \\ 3 PDIZ/UFPB/Areia-PB. Professora do curso de Zootecnia/UVA - Sobral, CE. Bolsista da Funcap. \\ ${ }^{4}$ Departamento de Zootecnia/CCA/UFPB - Areia, PB. Bolsista do CNPq. \\ 5 Departamento de Zootecnia/UNESP - Jaboticabal, SP. \\ ${ }^{6}$ Departamento de Engenharia Agrícola/UFCG - Campina Grande, PB.
}

José Humberto Vilar da Silva1, José Anchieta de Araujo², Cláudia de Castro Goulart ${ }^{3}$, Fernando Guilherme Perazzo Costa ${ }^{4}$, Nilva Kazue Sakomura ${ }^{5}$, Dermeval Araújo Furtado ${ }^{6}$

RESUMO - Dois experimentos foram realizados para avaliar a interação fósforo disponível $(\mathrm{Pd}) \times$ fitase $(\mathrm{UF})$ da dieta sobre o desempenho, os níveis plasmáticos de fósforo e os parâmetros ósseos de poedeiras. No experimento 1 , utilizaram-se 240 aves com 40 semanas de idade distribuídas em esquema fatorial $5 \times 2$, composto de cinco níveis de fósforo disponível ( 0,094 ; 0,$194 ; 0,294 ; 0,394$ e $0,494 \%$ ) e dois de fitase ( 0 e 300 unidades de fitase - UF). No experimento 2 , utilizaram-se 288 aves com 44 semanas de idade, distribuídas também em esquema fatorial $3 \times 4$, composto de três níveis de fósforo disponível (0,094; $0,294$ e $0,494 \%)$ e quatro de fitase $(0 ; 300 ; 600$ e 1.200 UF). No experimento 1 , não houve interação fósforo disponível $\times$ fitase, mas o nível de fósforo disponível influenciou, de forma quadrática, a produção (PR) e a massa (MO) de ovos, os níveis plasmáticos de fósforo e a conversão por massa de ovos (CMO) e, de forma linear, o teor de cinzas na tíbia (CT) e a resistência óssea (RO). A adição de 300 UF elevou a disponibilidade do fósforo (de 4,034 para 4,784 mg/dL), o teor de CT (de 41,55 para $42,90 \%$ ) e a resistência óssea (de 9,678 para $11,135 \mathrm{kgf} / \mathrm{mm}$ ). No experimento 2, a produção aumentou de forma linear com os níveis de fósforo disponível da ração, que aumentaram linearmente com o aumento do nível de fitase. Os teores de cinzas na tíbia aumentaram até o nível de 567 UF. O aumento do fósforo disponível no nível de 600 UF melhorou de forma linear a massa de ovos, a conversão por massa de ovos e a conversão por dúzia de ovos. A suplementação da ração com menor teor de fósforo disponível $(0,094 \%)$ com 300 a 1.200 UF melhorou a resistência óssea das aves. Poedeiras exigem em média 0,31 a $0,34 \%$ Pd. A adição de 300 UF ou o aumento do fósforo disponível em rações com 600 UF melhora a conversão por massa de ovos. A suplementação de rações deficientes em fósforo disponível com pelo menos 300 UF aumenta os níveis plasmáticos de fósforo, os teores de cinzas na tíbia e a resistência óssea de poedeiras comerciais.

Palavras-chave: enzima, poedeiras de ovos marrons, produção de ovos

\section{Available phosphorus and phytase interaction in the diet on performance, plasma phosphorus levels and bone parameters of commercial laying hens}

ABSTRACT - Two experiments were carried out to evaluate available phosphorus $(\mathrm{aP}) \times$ phytase interaction of the diet on performance, phosphorus plasma levels and bone parameters of laying hens. In experiment 1,240 birds with 40 weeks old, were distributed in a $5 \times 2$ factorial arrangement, composed of five levels of available phosphorus $(0.094 ; 0.194$; $0.294,0.394$ and $0.494 \%$ ) and two of phytase levels (0 and 300 Phytase Units - PU). In experiment 2, 288 birds with 44 weeks old were distributed in a $3 \times 4$ factorial arrangement, composed of three levels of available phosphorus $(0.094,0.294$ and $0.494 \%)$ and four phytase levels $(0,300,600$ and 1,200 PU). In experiment 1, there was no available phosphorus $\times$ phytase interaction, but available phosphorus level quadraticaly influenced egg production and egg mass, phosphorus plasma levels and feed conversion by egg mass (FCEM) and, in a linear fashion, tibia ashes content and bone strength. The addition of $300 \mathrm{PU}$ increased the availability of phosphorus (from 4.034 to $4.784 \mathrm{mg} / \mathrm{dL}$ ), tibia ashes content (from 41.55 to $42.90 \%$ ) and bone strength (from 9.678 to $11.135 \mathrm{kgf} / \mathrm{mm}$ ). In experiment 2, egg production increased in a linear fashion with dietary available phosphorus levels, which increased linearly with the increased phytase level. Tibia ashes content increased up to $567 \mathrm{PU}$. The increase in available phosphorus in of $600 \mathrm{PU}$ level improved in a linear fashion the egg mass, FCEM or feed conversion dozen eggs. The supplementation of diet with lower of available phosphorus $(0.094 \%)$ levels with 300 to $1,200 \mathrm{PU}$ improved bone strength of the birds. Laying hens require on average 0.31 to $0.34 \%$ aP. Addition of 300 PU or increasing dietary available phosphorus with 600 PU improves FCEM. Supplementation of diets deficient in available phosphorus with at least $300 \mathrm{PU}$ increases phosphorus plasma levels, tibia ash content and bone strength of commercial laying hens.

Key Words: brown laying hens, egg production, enzyme

Este artigo foi recebido em 15/10/2007 e aprovado em 16/5/2008.

Correspondências devem ser enviadas para jvilar@cft.ufpb.br. 


\section{Introdução}

$\mathrm{O}$ fósforo $(\mathrm{P})$ é o segundo mineral mais exigido e o terceiro nutriente mais caro na ração de aves; participa do processo de formação dos ossos, das reações envolvendo gasto de energia a partir do ATP, na formação dos ácidos nucléicos, e está presente nos fosfolipídeos das membranas plasmáticas e nos tecidos moles do corpo.

A maior parte do fósforo nos grãos encontra-se ligada ao fitato e tem disponibilidade de 40 a 25\% (Kies et al., 1997). Desta forma, utilização de fitase exógena aumenta a disponibilidade de fósforo, reduzindo a necessidade de suplementação das dietas com fósforo inorgânico e, conseqüentemente, a excreção de fósforo, sem afetar o desempenho das aves (Yu et al., 2004).

Apesar do alto conteúdo de ácido fítico e da grande proporção de fósforo indisponível, a maior parte das experiências anteriores com a adição de fitase em rações à base de milho e farelo de soja tem sido insatisfatória. As razões teóricas podem estar associadas ao tipo de ingrediente usado nos testes pelas indústrias. É possível que o nível de fitase sugerido para rações com $15 \%$ ou mais de farelo de arroz, que, segundo Borges (1997), apresenta apenas 14\% de fósforo disponível, seja baixo para rações à base de milho e farelo de soja, cujo nível de fitato é menor. Obviamente, níveis elevados de fitase não são econômicos e estudos de exigências nutricionais de fósforo com adição de fitase às rações devem ser realizados para obtenção de estimativas que otimizem a concentração desse mineral na dieta.

As recomendações na literatura dos níveis de fósforo disponível para poedeiras são muito discrepantes e provavelmente não refletem os níveis ideais de incorporação de novos aditivos, como a fitase, nas matrizes de formulação das rações. O NRC (1994) sugere $0,25 \%$, enquanto Rostagno et al. (2005) indicaram $0,375 \%$, que equivalem a uma diferença de $50 \%$ entre a menor e a maior recomendação.

Poucos estudos têm sido realizados para avaliar a influência da fitase nas exigências de fósforo disponível para poedeiras em níveis superiores às recomendações da indústria.

Considerando a grande discrepância nas recomendações de fósforo disponível para poedeiras na literatura, a baixa eficiência de utilização do fósforo no intestino das aves (Yu et al., 2004) e a existência de fatores que afetam a absorção de fósforo, como a relação $\mathrm{Ca}: \mathrm{Pd}$, e considerando ainda a fitase como opção para aumentar a disponibilidade da fração de fósforo orgânico e reduzir a necessidade de suplementação de fósforo disponível nas dietas, realizou-se este estudo para avaliar a exigência de fósforo disponível e o efeito da adição de fitase em rações à base de milho e farelo de soja sobre o desempenho, os níveis plasmáticos de fósforo e os parâmetros ósseos de poedeiras.

\section{Material e Métodos}

Dois experimentos foram realizados no Setor de Avicultura do Centro de Formação de Tecnólogos, Campus de Bananeiras da Universidade Federal da Paraíba (UFPB), em dois galpões experimentais abertos nas laterais, com pé-direito de $2 \mathrm{~m}$, largura de $4 \mathrm{~m}$ e comprimento de $26 \mathrm{~m}$, e cobertura de telhas de barro em duas águas e duas fileiras duplas de gaiolas de arame galvanizado, separadas por um corredor central de $0,8 \mathrm{~m}$.

No experimento 1, foram utilizadas 240 poedeiras semipesadas Lohmann Brown, alojadas em densidade de $550 \mathrm{~cm}^{2} /$ ave, com 20 semanas de idade e peso inicial de $1,7 \pm 0,542 \mathrm{~kg}$. As aves foram selecionadas pelo peso vivo e, depois de duas semanas de alimentação com uma dieta única, foram submetidas a nova seleção com base na produção de ovos.

O experimento foi desenvolvido em delineamento inteiramente ao acaso, em esquema fatorial $5 \times 2$ (cinco níveis de fósforo disponível $\times$ dois níveis de fitase), que resultaram em dez tratamentos, com cinco repetições, cada uma composta de seis aves. As rações experimentais foram balanceadas para atender às exigências nutricionais das aves (Rostagno et al., 2005), exceto de fósforo disponível (Tabela 1).

Os níveis de fósforo disponível estudados foram 0,094; 0,194; 0,294; 0,394 e 0,494\%, obtidos com a suplementação com fosfato bicálcico (FBI) nos nível de 0,$00 ; 0,54 ; 1,08 ; 1,62$ e 2,16\% com a retirada simultânea do cálcio proveniente do calcário, mantendo as dietas isocálcicas. Em seguida, as dietas foram suplementadas com $300 \mathrm{UF}$ ou $60 \mathrm{~g}$ de Natuphos ${ }^{\circledR} / \mathrm{t}$ em substituição à areia lavada, conforme sugestão e garantia de atividade do produto pela indústria. Uma unidade de fitase (UF) corresponde à quantidade de fitase que libera $1 \mathrm{mmol}$ de fósforo inorgânico por minuto a partir de $0,0051 \mathrm{~mol} / \mathrm{L}$ de fitato de sódio a $37^{\circ} \mathrm{C} \mathrm{e} \mathrm{pH} \mathrm{de} \mathrm{5,5.}$ A enzima utilizada foi da marca comercial Natuphos, fornecida pela BASF, obtida pela fermentação utilizando fungos do grupo Aspergillus niger, e com atividade inicial mínima de $5.000 \mathrm{UF} / \mathrm{g}$, segundo o fabricante.

O experimento foi realizado em seis subperíodos de 28 dias e foi concluído quando as aves atingiram 44 semanas de idade. Ao final de cada subperíodo, as sobras de ração dos comedouros e baldes foram pesadas e o consumo de ração foi calculado pela diferença entre a ração fornecida e as sobras de ração. 
Tabela 1 - Composição das rações experimentais, na matéria natural

\begin{tabular}{|c|c|c|c|c|c|}
\hline \multirow[t]{2}{*}{ Ingrediente } & \multicolumn{5}{|c|}{$\% \mathrm{Pd}$} \\
\hline & 0,094 & 0,194 & 0,294 & 0,394 & 0,494 \\
\hline Milho, $8,8 \%$ PB & 61,011 & 61,011 & 61,011 & 61,011 & 61,011 \\
\hline Farelo de soja, $45 \%$ PB & 23,869 & 23,869 & 23,869 & 23,869 & 23,869 \\
\hline Calcário & 10,691 & 10,342 & 9,993 & 9,643 & 9,295 \\
\hline Fosfato bicálcico & 0,000 & 0,540 & 1,081 & 1,622 & 2,161 \\
\hline DL-metionina, $99 \%$ & 0,173 & 0,173 & 0,173 & 0,173 & 0,173 \\
\hline Óleo & 2,303 & 2,303 & 2,303 & 2,303 & 2,303 \\
\hline Sal comum & 0,543 & 0,543 & 0,543 & 0,543 & 0,543 \\
\hline Cloreto de colina & 0,150 & 0,150 & 0,150 & 0,150 & 0,150 \\
\hline Premix vitamínico ${ }^{1}$ & 0,150 & 0,150 & 0,150 & 0,150 & 0,150 \\
\hline Premix mineral $^{2}$ & 0,100 & 0,100 & 0,100 & 0,100 & 0,100 \\
\hline Inerte ${ }^{3}$ & 1,000 & 0,809 & 0,617 & 0,426 & 0,231 \\
\hline $\mathrm{BHT}^{4}$ & 0,010 & 0,010 & 0,010 & 0,010 & 0,010 \\
\hline Fitase $^{5}$ & 0,000 & 0,000 & 0,000 & 0,000 & 0,000 \\
\hline \multicolumn{6}{|l|}{ Composição química } \\
\hline $\mathrm{EM}, \mathrm{kcal} / \mathrm{kg}$ & 2.800 & 2.800 & 2.800 & 2.800 & 2.800 \\
\hline $\mathrm{PB}, \%$ & 16,200 & 16,200 & 16,200 & 16,200 & 16,200 \\
\hline Metionina digestível, \% & 0,430 & 0,430 & 0,430 & 0,430 & 0,430 \\
\hline Metionina+cistina digestível, \% & 0,700 & 0,700 & 0,700 & 0,700 & 0,700 \\
\hline Lisina digestível, \% & 0,816 & 0,816 & 0,816 & 0,816 & 0,816 \\
\hline Treonina digestível, \% & 0,626 & 0,626 & 0,626 & 0,626 & 0,626 \\
\hline Arginina digestível, \% & 1,039 & 1,039 & 1,039 & 1,039 & 1,039 \\
\hline Cálcio, \% & 4,200 & 4,200 & 4,200 & 4,200 & 4,200 \\
\hline Fósforo, \% & 0,285 & 0,384 & 0,484 & 0,585 & 0,684 \\
\hline Fósforo disponível, \% & 0,094 & 0,194 & 0,294 & 0,394 & 0,494 \\
\hline Sódio, \% & 0,250 & 0,250 & 0,250 & 0,250 & 0,250 \\
\hline
\end{tabular}

A produção de ovos foi anotada diariamente e, para determinação do peso dos ovos, foram realizadas coletas e pesagens de todos os ovos dos últimos cinco dias de cada subperíodo experimental. No cálculo da massa de ovos (MO), a produção de ovos foi multiplicada pelo peso dos ovos e, posteriormente, a conversão por massa de ovos foi calculada pela relação entre o consumo de ração e a massa de ovos produzida. A qualidade da casca foi estimada pela gravidade específica, segundo método descrito por Hempe et al. (1988).

Uma ave por parcela foi sangrada na jugular e amostras de sangue foram coletadas em frascos e centrifugadas a $4.000 \mathrm{rpm}$ durante 15 minutos para análises dos níveis de fósforo no plasma $(\mathrm{Pp})$ utilizando-se Kit Labtest e espectrofotômetro por colorimetria.

A resistência óssea foi determinada nas tíbias esquerdas das aves, submetidas ao teste de resistência à quebra. As tíbias direitas, após a retirada da gordura no extrator Soxhlet, foram mantidas em mufla a $600^{\circ} \mathrm{C}$ durante 4 horas (Silva, 1991) para determinação dos teores de cinzas (CT). A resistência óssea (RO) da tíbia esquerda foi avaliada em prensa mecânica no Laboratório de Engenharia Civil da
Universidade Federal de Campina Grande, Paraíba. Os ossos foram colocados na posição horizontal sobre dois suportes e submetidos à pressão, aplicada no centro de cada osso. A quantidade máxima de força aplicada no osso antes de sua ruptura foi considerada resistência à quebra.

Noexperimento 2, utilizaram-se 288 poedeiras semipesadas Lohmann Brown, peso inicial de 1,65 $\pm 0,125 \mathrm{~kg}$, selecionadas às 26 semanas de idade e alojadas nas mesmas condições do experimento 1 . As aves foram distribuídas em delineamento inteiramente ao acaso, em esquema fatorial $3 \times 4$ (três níveis de fósforo disponível $\times$ quatro unidades de fitase $-U F$ ), resultando em 12 tratamentos com quatro repetições de seis aves. As rações 1, 3 e 5 do experimento anterior (Tabela 1 ) foram escolhidas por conterem apenas fósforo orgânico $(0,285 \%$ de Pt e $0,094 \%$ de $\mathrm{Pd})$, maior teor de fósforo orgânico $(0,285 \%)$ e menor de fósforo inorgânico $(0,199 \%)$, mas que atendia às exigências das aves $(0,484 \%$ PT e $0,294 \%$ Pd), menor teor de fósforo orgânico $(0,294 \%)$ e maior de fósforo inorgânico $(0,399 \%)$, mas com excesso de fósforo disponível $(0,684 \%$ PT e $0,494 \%$ Pd). Cada dieta foi suplementada com um dos níveis de fitase comercial $(0,60$, 120 ou $240 \mathrm{~g}$ de Natuphos $5000^{\circledR} / \mathrm{t}$ ração) em substituição ao 
inerte (areia lavada), fornecendo o equivalente a 0, 300, 600 ou $1.200 \mathrm{UF} / \mathrm{kg}$ de ração.

O experimento foi conduzido até as aves atingirem 50 semanas de idade (seis subperíodos de 28 dias). Foram avaliados o consumo de ração (CR), a produção de ovos (PR), o peso dos ovos (PO), a gravidade específica da casca (GE), o nível plasmático de fósforo $(\mathrm{Pp})$, o teor de cinzas na tíbia (CT), a massa de ovos (MO), as conversões por massa de ovos (CMO) e por dúzia de ovos (CDO) e a resistência óssea (RO). Todas as variáveis foram mensuradas de acordo com as metodologias citadas no experimento anterior.

Os resultados dos dois experimentos foram analisados pelo teste $\mathrm{F}(\mathrm{P}<0,05)$ e, quando as interações foram significativas, os efeitos de cada nível de um fator principal foram estudados dentro do outro. Na ausência de interação significativa, os efeitos principais foram avaliados pelo teste $\mathrm{SNK}(\mathrm{P}<0,05)$.

As estimativas de exigência de fósforo disponível foram obtidas pelos modelos quadrático e linear response plateau (LRP), considerando o nível de significância, o valor do coeficiente de determinação e a resposta biológica das aves.

\section{Resultados e Discussão}

No experimento 1, a interação níveis de fósforo disponível $\times$ níveis de fitase da ração não teve efeito $(\mathrm{P}>0,05)$ sobre o consumo de ração, a produção de ovos, o peso dos ovos e a massa de ovos (Tabela 2). A adição de fitase (300 UF) também não teve efeito sobre estas variáveis, mas o nível de fósforo disponível influenciou de forma quadrática $(\mathrm{P} \leq 0,05)$ a produção e a massa de ovos (Tabela 2). Os níveis de fósforo disponível abaixo da exigência das aves não causaram redução no consumo das poedeiras, o que está de acordo com estudos realizados por Vieira et al. (2001) e Barkley et al. (2004), que também não observaram redução significativa do consumo de rações deficientes em fósforo disponível.

Considerando a produção de ovos, a exigência estimada pelo modelo de regressão quadrático $(\hat{\mathrm{Y}}=73,9109+$ $\left.82,5156 \mathrm{X}-140,968 \mathrm{X}^{2} ; \mathrm{r}^{2}=0,70\right)$ foi de $0,29 \%$ de fósforo disponível na ração (Figura 1). Esse resultado corrobora o valor estimado por Borrmann et al. (2001), de 0,29\% de fósforo disponível para poedeiras leves, no entanto, foi superior ao recomendado pelo NRC (1994), de 0,25\%, e menor que o sugerido por Rostagno et al. (2005), de 0,375\%, para poedeiras semipesadas.

A massa de ovos foi afetada de forma quadrática (Figura 2) pelos níveis de $\mathrm{Pd}$ da ração $(\mathrm{P}<0,05)$, conforme a equação $\hat{\mathrm{Y}}=48,9255+56,6211 \mathrm{X}-97,3267 \mathrm{X}^{2}\left(\mathrm{r}^{2}=0,62\right)$.
Tabela 2 - Consumo de ração (CR), produção (PR), peso (PO) e massa de ovos (MO) de poedeiras alimentadas com rações contendo diversos níveis de fósforo disponível (Pd) e fitase (UF)

\begin{tabular}{|c|c|c|c|c|}
\hline $\mathrm{Pd}(\%)$ & CR (g) & PR (\%) & $\mathrm{PO}(\mathrm{g})$ & MO (g) \\
\hline 0,094 & 112,71 & 79,59 & 66,11 & 52,55 \\
\hline 0,194 & 117,93 & 87,04 & 67,53 & 58,44 \\
\hline 0,294 & 114,26 & 83,72 & 66,69 & 55,62 \\
\hline 0,394 & 112,41 & 85,14 & 65,79 & 55,98 \\
\hline 0,494 & 111,88 & 80,35 & 66,59 & 53,47 \\
\hline \multicolumn{5}{|l|}{ UF } \\
\hline 0 & 114,75 & 83,45 & 66,02 & 54,86 \\
\hline 300 & 112,93 & 82,88 & 67,06 & 55,57 \\
\hline \multicolumn{5}{|l|}{ ANOVA } \\
\hline \multicolumn{5}{|l|}{$\mathrm{Pd}$} \\
\hline $\mathrm{L}$ & ns & ns & ns & ns \\
\hline Q & $\mathrm{ns}$ & $* * *$ & ns & $* * *$ \\
\hline UF & $\mathrm{ns}$ & ns & ns & ns \\
\hline $\mathrm{Pd} \times \mathrm{UF}$ & $\mathrm{ns}$ & ns & ns & ns \\
\hline CV (\%) & 6,12 & 5,39 & 2,70 & 5,60 \\
\hline
\end{tabular}

Efeito: $\mathrm{L}=$ linear; $\mathrm{Q}=$ quadrático; ${ }^{* *}(\mathrm{P}<0,01) ;{ }^{* *}(\mathrm{P}<0,001)$.

A exigência estimada em $0,29 \%$ foi semelhante à estimada considerando a produção de ovos. Barkley et al. (2004) também observaram efeito significativo da deficiência de fósforo disponível na redução da produção de massa de ovos.

A adição de fitase (300 UF) não afetou a produção de ovos, o consumo de ração, o peso e a massa de ovos das galinhas. Outros pesquisadores também não encontraram efeitos significativos da suplementação de fitase na dieta sobre a produção, o peso dos ovos, o ganho de peso e o consumo de ração em poedeiras (Boling et al., 2000; Liebert et al., 2005).

Também não foi detectada interação significativa ( $\mathrm{P}>0,05)$ dos níveis de fósforo disponível e níveis de fitase para as conversões por massa e por dúzia de ovos, a gravidade específica, o nível plasmático de fósforo, o teor de cinzas na tíbia e a resistência óssea (Tabela 3 ).

Os níveis de fósforo disponível da ração influenciaram de forma quadrática $(\mathrm{P} \leq 0,05)$ a conversão por massa de ovos, $\hat{Y}=2,28850-1,66001 X+2,65029 X^{2}\left(r^{2}=0,70\right)$, de modo que a exigência de fósforo disponível foi estimada em $0,31 \%$ (Figura 3 ).

O nível máximo de fósforo no plasma (4,989 mg P/dL) estimado pelo modelo quadrático (Figura 4) ocorreu quando fornecido o nível de $0,49 \%$ de $\operatorname{Pd}$ ( $\hat{Y}=2,57168+9,96902 X$ - 10,2768 X $\left.\mathrm{X}^{2} ; \mathrm{r}^{2}=0,92\right)$, enquanto, pelo modelo linear response plateau (LRP), o nível máximo de fósforo no plasma $(4,817 \mathrm{mg} \mathrm{P} / \mathrm{dL})$ foi estimado no nível de $0,41 \%$ $\left(\hat{\mathrm{Y}}=2,8630+4,6625 \mathrm{X} ; \mathrm{r}^{2}=0,95\right)$.

Houve efeito linear crescente $(\mathrm{P} \leq 0,05)$ do nível de fósforo disponível sobre o teor de cinzas na tíbia, conforme 


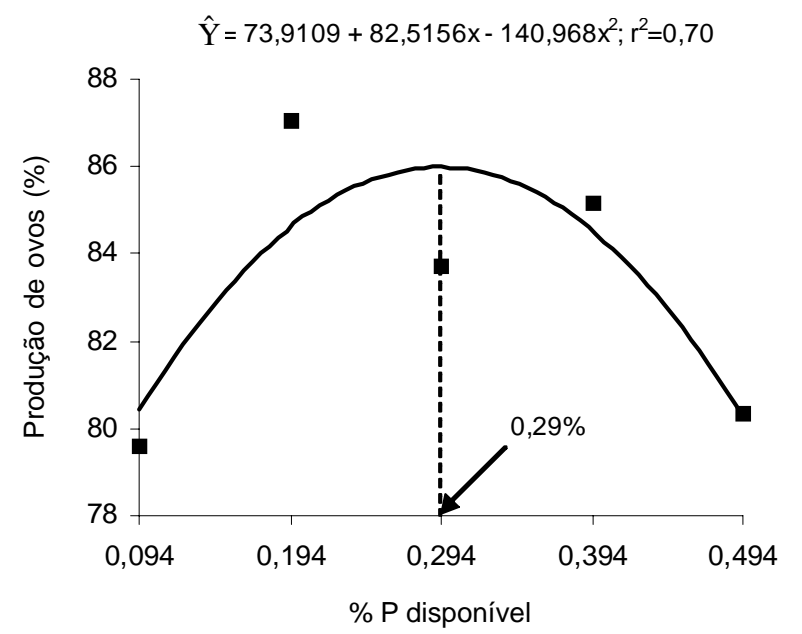

Figura 1 - Produção de ovos de poedeiras semipesadas alimentadas com rações contendo diversos níveis de fósforo disponível.

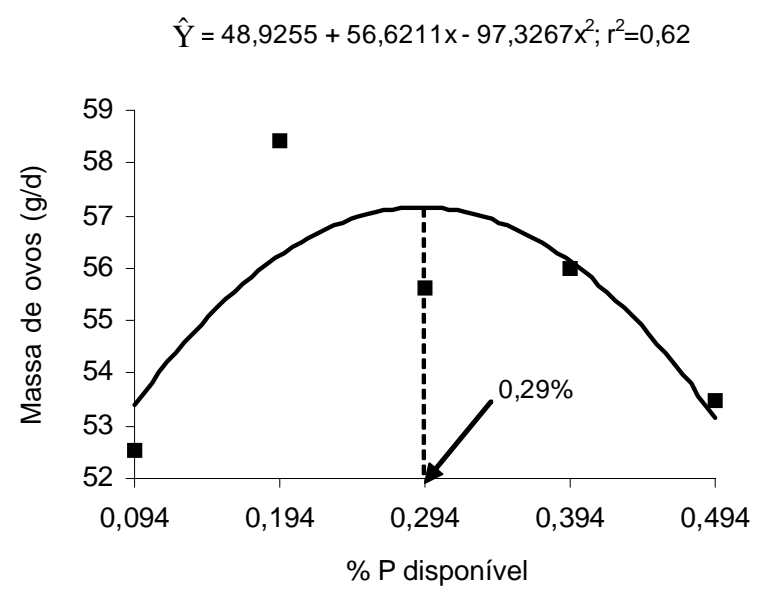

Figura 2 - Massa de ovos de poedeiras alimentadas com rações contendo diversos níveis de fósforo disponível.

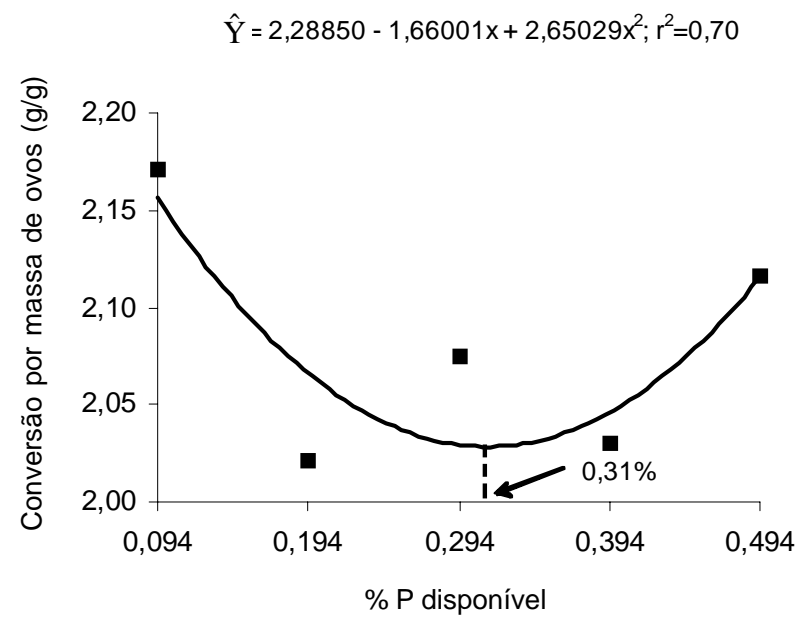

Figura 3 - Conversão por massa de ovos de poedeiras alimentadas com rações com diversos níveis de fósforo disponível.

a equação $\hat{Y}=40,9087+4,47375 X\left(r^{2}=0,36\right)$, indicando que, a cada $1 \%$ de fósforo disponível na ração, o teor de cinzas na tíbia aumentou $4,47 \%$. A resistência óssea aumentou de forma linear $(\mathrm{P} \leq 0,01)$ quando o nível de fósforo disponível na ração foi elevado, conforme a regressão $\hat{Y}=7,37539+$ $10,3084 X\left(r^{2}=0,91\right)$.

Resultado semelhante foi observado por Waldroup et al. (2000) com a adição de fitase (800 UF) na ração de frangos de corte de 1 a 21 dias de idade. O aumento do nível plasmático de fósforo com a suplementação da ração com fitase corrobora os estudos realizados por Shirley et al. (2003) com frangos de corte de 1 a 16 dias utilizando dieta deficiente em fósforo disponível $(0,19 \%)$ suplementada com níveis crescentes de fitase (de 0 a 12.000 UF). Onyango et al. (2003) também constataram alta correlação entre o

Tabela 3 - Conversão alimentar por massa (CMO) e por dúzia de ovos (CDZ), gravidade específica da casca dos ovos (GE), nível de fósforo no plasma (Pp), teor de cinzas na tíbia (CT) e resistência óssea (RO) de poedeiras alimentadas com rações contendo diversos níveis de fósforo disponível (Pd) e fitase (UF)

\begin{tabular}{|c|c|c|c|c|c|c|}
\hline $\mathrm{Pd}(\%)$ & CMO $(\mathrm{kg} / \mathrm{kg})$ & $\mathrm{CDZ}(\mathrm{kg} / \mathrm{dz})$ & $\mathrm{GE}\left(\mathrm{g} / \mathrm{cm}^{3}\right)$ & $\mathrm{Pp}(\mathrm{mg} / \mathrm{dL})$ & $\mathrm{CT}(\%)$ & $\mathrm{RO}(\mathrm{kgf} / \mathrm{mm})$ \\
\hline 0,094 & 2,171 & 1,719 & 1,090 & 3,301 & 41,49 & 8,927 \\
\hline 0,194 & 2,021 & 1,645 & 1,090 & 4,350 & 40,80 & 8,601 \\
\hline 0,294 & 2,075 & 1,658 & 1,088 & 4,621 & 42,76 & 10,240 \\
\hline 0,394 & 2,030 & 1,602 & 1,089 & 4,664 & 43,86 & 11,760 \\
\hline 0,494 & 2,116 & 1,691 & 1,090 & 5,108 & 42,20 & 12,502 \\
\hline \multicolumn{7}{|l|}{ UF } \\
\hline 0 & $2,110 \mathrm{a}$ & 1,670 & 1,090 & $4,034 b$ & $41,55 b$ & $9,678 \mathrm{~b}$ \\
\hline 300 & $2,055 b$ & 1,656 & 1,089 & $4,784 \mathrm{a}$ & $42,90 \mathrm{a}$ & $11,135 \mathrm{a}$ \\
\hline \multicolumn{7}{|l|}{ ANOVA } \\
\hline \multicolumn{7}{|l|}{$\mathrm{Pd}$} \\
\hline $\mathrm{L}$ & $\mathrm{ns}$ & ns & $\mathrm{ns}$ & $* *$ & * & $* *$ \\
\hline Q & $\mathrm{ns}$ & ns & $\mathrm{ns}$ & $* *$ & * & $* *$ \\
\hline UF & * & $\mathrm{ns}$ & $\mathrm{ns}$ & * & * & * \\
\hline $\mathrm{Pd} \times \mathrm{UF}$ & ns & ns & $\mathrm{ns}$ & $* *$ & * & * \\
\hline CV (\%) & 6,73 & 7,42 & 0,84 & 11,97 & 4,67 & 17,975 \\
\hline
\end{tabular}

a,b Letras distintas indicam diferenças significativas entre médias pelo teste $F(P<0,05)$. Efeito; $Q=$ quadrático; ${ }^{*}(P<0,05) ;{ }^{* *}(P<0,01)$. 


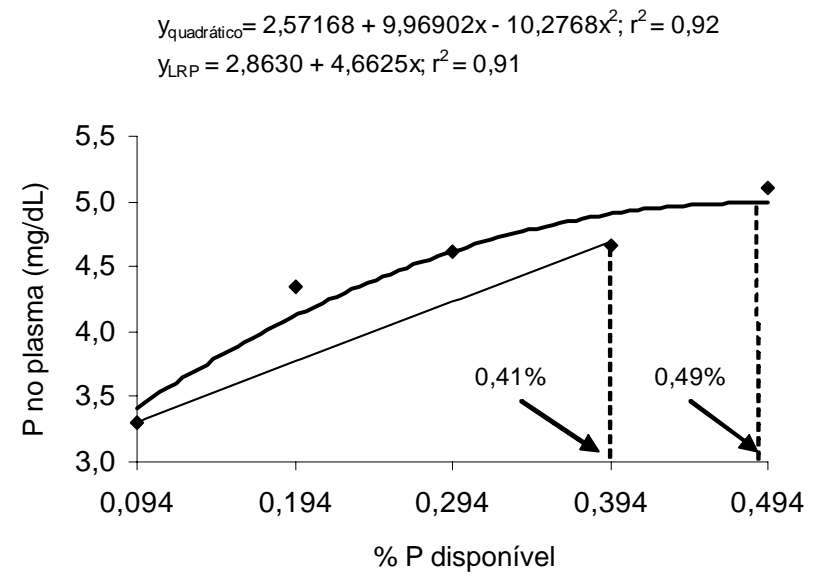

Figura 4 - Fósforo total no plasma de poedeiras alimentadas com rações contendo diversos níveis de fósforo disponível.

nível de fósforo disponível da ração e o teor de cinzas da tíbia de pintos de corte de 1 a 21 dias de idade.

Ao contrário das respostas observadas no consumo de ração, na produção de ovos, no peso e na massa de ovos, a suplementação da ração com 300 UF melhorou $(\mathrm{P}<0,05)$ a conversão por massa de ovos, o nível plasmático de fósforo, o teor de cinzas na tíbia e a resistência óssea (Tabela 3), resultados indicativos da melhora na eficiência de utilização do fósforo fítico da ração e da possível redução na excreção e na poluição do meio ambiente, especialmente em regiões de alta densidade de criação de aves. Rowland et al. (1968) também observaram aumento na resistência do osso à quebra quando o conteúdo de cinzas da tíbia de poedeiras aumentou.

A adição de fitase não influenciou a produção de ovos, mas melhorou a conversão alimentar por massa de ovos e aumentou significativamente os níveis plasmáticos de fósforo e o teor de cinzas nos ossos, o que indica reais benefícios econômicos e ambientais da suplementação dessa enzima em rações para poedeiras.

A suplementação da ração mais deficiente em fósforo disponível com fitase (300 UF) melhorou o teor de cinzas na tíbia em $2,8 \%$, a produção de ovos em $5 \%$, o peso dos ovos em $3 \%$, a massa de ovos em $7 \%$ e a conversão alimentar por dúzia de ovos em $3 \%$ em comparação às aves alimentadas com a mesma dieta sem fitase. Esses resultados, apesar de não-significativos, podem ser economicamente atrativos. Em poedeiras alimentadas com dietas deficientes em fósforo $(0,11 \%$ de Pd) suplementadas com fitase (300 UF/kg), Wu et al. (2006) constataram aumento na produção e na massa de ovos, cujos valores foram semelhantes aos obtidos nas aves alimentadas com a dieta controle $(0,38 \% \mathrm{Pd})$.
No experimento 2, do mesmo modo que no experimento 1, não houve interação $(\mathrm{P}>0,05)$ dos níveis de $\mathrm{Pd}$ e de fitase (UF) para a produção de ovos, o consumo de ração, o peso dos ovos, a gravidade específica da casca, o nível plasmático de fósforo e a porcentagem de cinzas na tíbia (Tabela 4). Costa et al. (2004), em experimento com poedeiras, também não constataram interação dos níveis de fósforo disponível $(0,37$; $0,30$ e $0,20 \%)$ e níveis de fitase $(0 ; 500$ e 1.000 UF) da ração.

O consumo de ração, o peso dos ovos e a gravidade específica não foram afetados por nenhum dos fatores principais $(\mathrm{P}>0,05)$, o que confirma os resultados do experimento anterior. Vieira et al. (2001), utilizando duas dietas contendo em torno de $16 \%$ de fósforo disponível suplementadas com $0 ; 200 ; 300$ e 400 UF, não encontraram efeito sobre o consumo de ração em poedeiras durante o segundo ciclo de produção.

Neste estudo, verificou-se efeito linear positivo do nível de fósforo disponível sobre a produção de ovos, conforme a equação $\hat{\mathrm{Y}}=76,9695+14,0219 \mathrm{X}\left(\mathrm{r}^{2}=0,71\right)$, de modo que a cada aumento de $1 \%$ de fósforo disponível na ração, a produção de ovos aumentou $(\mathrm{P}<0,01) 15 \%$ e a porcentagem de cinzas na tíbia 7,8\% ( $\left.\hat{\mathrm{Y}}=40,5193+7,86094 \mathrm{X} ; \mathrm{r}^{2}=0,97\right)$. O valor máximo foi observado com $0,494 \%$ de fósforo disponível na ração, resultado semelhante ao observado no experimento 1 , no qual os teores de cinzas na tíbia aumentaram até o nível de $0,494 \%$ de fósforo disponível.

$\mathrm{O}$ aumento do nível de fitase na ração também não afetou $(\mathrm{P}>0,05)$ o consumo de ração, a produção, o peso e a gravidade específica dos ovos, o que confirma os resultados do experimento 1. Entretanto, o aumento do nível de fitase de 0 para 1.200 de UF melhorou linearmente $(\mathrm{P}<0,05)$, independentemente do nível de fósforo da ração, o nível de fósforo no plasma, enquanto a porcentagem de cinzas na tíbia apresentou comportamento quadrático $(\mathrm{P}<0,05)$, conforme a equação $\hat{Y}=41,8961+0,00861530 X-0,000007595 X^{2}$ $\left(r^{2}=0,94\right)$, com ponto de máxima deposição de cinzas na tíbia estimado no nível de fitase de 567 UF. Esse resultado difere do obtido por Vieira et al. (2001), que não notaram efeito da adição de 0;200; 300 e 400 UF sobre a porcentagem de cinzas na tíbia de poedeiras.

Os níveis de fósforo no plasma aumentaram $0,0001 \mathrm{mg} / \mathrm{dL}$ a cada aumento de 1 UF na ração ( $\hat{Y}=4,18817+0,00170429 X$; $\left.r^{2}=0,79\right)$. Esse efeito da fitase no aumento do nível plasmático de fósforo ocorreu de forma independente ao nível de fósforo da ração e confirma o resultado do experimento 1 , no qual este parâmetro sangüíneo também melhorou com a suplementação de 300 UF. Conte et al. (2002), em estudo com frangos de corte de 32 a 37 dias de idade alimentados com uma ração contendo $0,16 \%$ de fósforo disponível 
Tabela 4 - Consumo de ração (CR), produção de ovos (PR), peso dos ovos (PO), gravidade específica da casca dos ovos (GE), fósforo plasmático $(\mathrm{Pp})$ e teor de cinzas na tíbia $(\mathrm{CT})$ de poedeiras alimentadas com rações contendo diversos níveis de fósforo disponível (Pd) e fitase (UF)

\begin{tabular}{|c|c|c|c|c|c|c|}
\hline $\mathrm{Pd}(\%)$ & CR, g/ave/dia & $\mathrm{PR}, \%^{1}$ & $\mathrm{PO}, \mathrm{g}$ & $\mathrm{GE}^{2}, \mathrm{~g} / \mathrm{cm}^{3}$ & $\mathrm{Pp}, \mathrm{mg} / \mathrm{dL}$ & $\mathrm{CT}, \%$ \\
\hline 0,094 & 111,14 & 77,62 & 64,41 & 1,093 & 4,694 & 41,102 \\
\hline 0,294 & 110,57 & 82,44 & 64,24 & 1,081 & 5,088 & 43,143 \\
\hline 0,494 & 110,42 & 83,22 & 63,48 & 1,092 & 6,755 & 44,246 \\
\hline \multicolumn{7}{|l|}{ UF } \\
\hline 0 & 110,16 & 79,58 & 64,34 & 1,089 & 4,324 & 41,926 \\
\hline 300 & 111,38 & 82,03 & 64,44 & 1,090 & 4,688 & 43,717 \\
\hline 600 & 110,46 & 79,20 & 62,86 & 1,097 & 4,724 & 44,391 \\
\hline 1.200 & 111,12 & 80,87 & 64,14 & 1,094 & 6,755 & 41,287 \\
\hline \multicolumn{7}{|l|}{ ANOVA } \\
\hline $\mathrm{Pd}$ & $\mathrm{ns}$ & $\mathrm{L} * * *$ & ns & $\mathrm{ns}$ & $\mathrm{ns}$ & $\mathrm{L}^{*}$ \\
\hline UF & ns & $\mathrm{ns}$ & $\mathrm{ns}$ & ns & $\mathrm{L} * * *$ & $\mathrm{Q}^{*}$ \\
\hline $\mathrm{Pd} \times \mathrm{UF}$ & $\mathrm{ns}$ & $\mathrm{ns}$ & $\mathrm{ns}$ & $\mathrm{ns}$ & $\mathrm{ns}$ & $\mathrm{ns}$ \\
\hline $\mathrm{CV}(\%)$ & 1,99 & 5,63 & 2,42 & 2,50 & 32,86 & 9,18 \\
\hline
\end{tabular}

${ }_{1}^{1}$ Efeito linear do fósforo disponível sobre a produção de ovos $(P \leq 0,001)$.

2 Efeito linear das unidades de fitase sobre os níveis séricos de fósforo.

${ }^{*} \mathrm{P} \leq 0,05 ;{ }^{* *} \mathrm{P} \leq 0,01 ;{ }^{* * *} \mathrm{P} \leq 0,01$

Tabela 5 - Massa (MO), conversão por massa (CMO) e por dúzia de ovos (CDZ) e resistência óssea (RO) em poedeiras alimentadas com rações contendo diversos níveis de fósforo disponível (Pd) e fitase (UF)

\begin{tabular}{|c|c|c|c|c|c|c|c|c|c|c|c|c|}
\hline \multirow[t]{3}{*}{ UF } & \multicolumn{3}{|c|}{ MO, g/ave/dia } & \multicolumn{3}{|c|}{$\mathrm{CMO}, \mathrm{kg} / \mathrm{kg}$} & \multicolumn{3}{|c|}{ CDZ, kg/dúzia } & \multicolumn{3}{|c|}{$\mathrm{RO}, \mathrm{kgf} / \mathrm{mm}$} \\
\hline & \multicolumn{3}{|c|}{$\mathrm{Pd}$} & \multicolumn{3}{|c|}{$\mathrm{Pd}$} & \multicolumn{3}{|c|}{$\mathrm{Pd}$} & \multicolumn{3}{|c|}{$\mathrm{Pd}$} \\
\hline & 0,094 & 0,294 & 0,494 & 0,094 & 0,294 & 0,494 & 0,094 & 0,294 & 0,494 & $0,094^{1}$ & 0,294 & 0,494 \\
\hline $0^{2}$ & 50,73 & 53,52 & 51,22 & 2,228 & 2,091 & 2,160 & 1,772 & 1,710 & 1,711 & 10,186 & 13,377 & 16,011 \\
\hline 300 & 51,64 & 51,18 & 54,03 & 2,216 & 2,201 & 2,113 & 1,768 & 1,691 & 1,651 & 13,851 & 14,589 & 12,342 \\
\hline $600^{3}$ & 46,03 & 52,48 & 53,67 & 2,517 & 2,160 & 2,060 & 1,960 & 1,655 & 1,626 & 13,136 & 12,166 & 14,536 \\
\hline 1.200 & 51,33 & 54,51 & 52,15 & 2,198 & 2,037 & 2,175 & 1,747 & 1,605 & 1,699 & 16,011 & 15,431 & 14,612 \\
\hline $\mathrm{Pd}$ & & $* * *$ & & & & $* * *$ & & & $* * *$ & & ns & \\
\hline UF & & $\mathrm{ns}$ & & & & $\mathrm{ns}$ & & & $\mathrm{ns}$ & & $* *$ & \\
\hline $\mathrm{Pd} \times \mathrm{UF}$ & & $* *$ & & & & $*$ & & & $* *$ & & $* *$ & \\
\hline $\mathrm{CV}(\%)$ & & 5,19 & & & & 7,29 & & & 5,49 & & 10,48 & \\
\hline
\end{tabular}

${ }^{1}$ Efeito linear do nível de fitase no nível de $0,094 \%$ de $P d$ sobre a $R O(P<0,05)$.

2 Efeito linear do $P d$ dentro no nível 0 de UF na ração sobre a $R O(P<0,05)$.

${ }^{3}$ Efeitos lineares do Pd dentro de nível 600 UF para a MO, CMO e CDZ (P $\left.\leq 0,001\right)$

${ }^{*}(\mathrm{P} \leq 0,05) ;{ }^{* *}(\mathrm{P} \leq 0,01) ;{ }^{* *}(\mathrm{P}<0,01) ; \mathrm{ns}=$ efeito não-significativo pelo teste $\mathrm{F}(\mathrm{P}>0,05)$.

suplementada com $0 ; 400 ; 800$ e 1.200 UF, também observaram aumento de 3,6 para 5,4; 6,5 e 7,3 mg/dL, respectivamente, nos níveis de fósforo no plasma.

Observou-se interação significativa $(\mathrm{P}<0,05)$ entre os níveis de fósforo disponível e os de fitase UF sobre a resistência óssea (Tabela 5), que melhorou de forma linear, $0,004 \mathrm{kgf} / \mathrm{mm}\left(\hat{\mathrm{Y}}=11,1030+0,00423824 \mathrm{X} ; \mathrm{r}^{2}=0,82\right)$, a cada acréscimo de 1 UF na ração com $100 \%$ de fósforo vegetal. Também houve melhora de 14,6 kgf/mm na resistência óssea a cada $1 \%$ de fósforo disponível na ração ( $\hat{Y}=8,91042+$ $14,5608 \times\left(r^{2}=0,85\right)$. A exigência de fósforo disponível estimada pelo modeloLRP $\left(\hat{\mathrm{Y}}=8,6715+16,0478 \mathrm{X} ; \mathrm{r}^{2}=0,91\right)$ na ração sem fitase foi de $0,34 \%$ para resistência óssea máxima de 14,22 kgf/mm. Essa exigência é mais alta que a estimada no experimento 1 , de $0,30 \%$, e próxima à recomendação de 0,375\%, de Rostagno et al. (2005).
Nas rações com 0,294 e 0,494\% de fósforo disponível suplementadas com fitase, assim como naquelas com $300 \mathrm{e}$ 1.200 UF com níveis crescentes de fósforo disponível, não foram constatados efeitos significativos, no entanto, o aumento do nível de fósforo disponível de 0,094\% para $0,494 \%$ quando a ração foi suplementada com fitase (600 UF) melhorou de forma linear a massa de ovos $(\mathrm{P} \leq 0,01)$, conforme a equação $\hat{\mathrm{Y}}=45,1020+19,1190 \mathrm{X}\left(\mathrm{r}^{2}=0,71\right)$, e a exigência de fósforo disponível foi estimada em $0,33 \%$ pelo modelo LRP, considerando o resultado de conversão por dúzia de ovos ( $\hat{Y}=2,0917-1,4051 X ; r^{2}=0,78$ ). Ao contrário desse resultado, Bormann et al. (2001) verificaram pior conversão alimentar por massa de ovos quando utilizaram fitase (300 UF) e aumentaram o nível de fósforo disponível da ração.

O efeito linear positivo sobre a conversão alimentar por massa de ovos quando as dietas com níveis crescentes de 
fósforo disponível foram suplementadas com 600 UF parece corroborar os resultados obtidos por Costa et al. (2004), que encontraram melhora linear na conversão alimentar por massa de ovos quando as rações à base de milho e farelo de soja foram suplementadas com 0, 500 e $1.000 \mathrm{UF}$.

No experimento 1, a adição de 300 UF aumentou de 9,68 para $11,14 \mathrm{kgf} / \mathrm{mm}$ a resistência óssea, independentemente do nível de fósforo disponível da ração, ao passo que, no experimento 2, o aumento do nível de fitase de 0 para 1.200 UF elevou a resistência óssea de 10,19 para $16,01 \mathrm{kgf} / \mathrm{mm}$ somente nas aves alimentadas com a ração com nível mais baixo de fósforo disponível. Esses resultados sugerem que a fitase aumenta a retenção de fósforo dietético no tecido ósseo e, portanto, reduz sua excreção, todavia, é possível obter maior resistência óssea com níveis de fitase superiores a 300 UF na ração.

Nenhuma interação significativa foi constatada entre os níveis de fósforo disponível e os de fitase para o peso do ovo e as porcentagens de gema, clara e casca dos ovos (Tabela 6), entretanto, na análise dos efeitos principais, verificaram-se redução de $1,64 \%$ na porcentagem de gema ( $\left.\hat{Y}=25,2687-1,64351 X ; r^{2}=0,74\right)$ e aumento de $2,39 \%$ na porcentagem de clara ( $\left.\hat{Y}=64,6019+2,3910 X ; r^{2}=0,79\right)$ a cada aumento de $1 \%$ no nível de fósforo disponível da ração. Costa et al. (2004) também não verificaram efeito de interação dos níveis de fósforo disponível com a fitase sobre as características internas do ovo.

Os resultados obtidos nos dois experimentos corroboram os descritos por Costa et al. (2004), que não encontraram efeitos de interação dos níveis de fósforo disponível e os de fitase em rações à base de milho e farelo de soja. No entanto, diferem daqueles recomendados por Boling et al. (2000), de 300 UF para uma dieta com $0,10 \%$ de fósforo disponível, e Bormann et al. (2001), que observaram menor exigência de fósforo $(0,26 \%)$ em poedeiras alimentadas com rações suplementadas com fitase (300 UF) em comparação à exigência estimada para poedeiras alimentadas com as mesmas rações sem fitase $(0,29 \%)$.

Entretanto, a suplementação com 300 UF, independentemente do nível de fósforo disponível (experimento 1), ou com 1.200 UF da ração mais deficiente em fósforo disponível $(0,094 \%)$ ou o aumento do fósforo disponível de 0,094 para 0,494\% (experimento 2) melhora os níveis plasmáticos de fósforo e os parâmetros ósseos, como cinzas na tíbia e resistência do osso à quebra.

O aumento dos níveis plasmáticos de fósforo, dos teores de cinzas na tíbia e da resistência óssea com a suplementação mínima de fitase (300 UF) pode ser usado como indicador da maior eficiência de uso e da menor excreção de fósforo em poedeiras alimentadas com rações à base de milho e farelo de soja, embora a margem de redução de fósforo com a suplementação da dieta com fitase não tenha sido determinada claramente neste trabalho. Segundo Casartelli et al. (2005), a fitase reduz a excreção de fósforo e a poluição ambiental em regiões de alta densidade de criação de aves.

Os aumentos do teor de cinzas na tíbia e da resistência óssea com a suplementação da ração com pelo menos 300 UF podem prevenir o desenvolvimento de patologias ósseas em poedeiras, como osteoporose e fadiga, que prejudicam o bem-estar e aumentam as perdas de aves por acidentes pela quebra de asas, pernas e pescoço durante o alojamento e as operações de retiradas das aves das gaiolas.

\section{Conclusões}

Poedeiras semipesadas exigem 0,31 a $0,34 \%$ de fósforo disponível na ração. A adição de fitase (300 UF) na ração melhora a conversão alimentar por massa de ovos, a concentração de fósforo no plasma, o teor de cinzas na tíbia e

Tabela 6 - Efeito do nível de fósforo disponível (Pd) e de fitase (UF) sobre as características interna e externa dos ovos

\begin{tabular}{|c|c|c|c|c|c|c|}
\hline $\begin{array}{l}\text { Tratamento } \\
\% \mathrm{Pd}\end{array}$ & Gema, g & Gema, \% & Clara, g & Clara, \% & Casca, g & Casca, \% \\
\hline 0,094 & 16,35 & 25,22 & 41,92 & 64,66 & 6,80 & 10,11 \\
\hline 0,294 & 16,22 & 24,60 & 44,14 & 65,49 & 6,52 & 9,89 \\
\hline 0,494 & 16,13 & 24,57 & 43,15 & 65,58 & 6,47 & 9,84 \\
\hline \multicolumn{7}{|l|}{ UF } \\
\hline 0 & 16,36 & 25,16 & 42,16 & 64,76 & 7,04 & 10,07 \\
\hline 300 & 16,11 & 24,76 & 42,47 & 65,22 & 6,52 & 10,01 \\
\hline 600 & 15,98 & 25,00 & 41,66 & 65,06 & 6,36 & 9,94 \\
\hline 1.200 & 16,50 & 24,67 & 43,84 & 65,44 & 6,62 & 9,88 \\
\hline \multicolumn{7}{|l|}{ Anova } \\
\hline $\mathrm{Pd}$ & $\mathrm{ns}$ & $\mathrm{L} * *$ & $\mathrm{~ns}$ & $\mathrm{~L} * * *$ & $\mathrm{~ns}$ & $\mathrm{~ns}$ \\
\hline UF & $\mathrm{Q} * *$ & $\mathrm{~ns}$ & ns & $\mathrm{ns}$ & $\mathrm{ns}$ & ns \\
\hline $\mathrm{Pd} \times \mathrm{UF}$ & $\mathrm{ns}$ & $\mathrm{ns}$ & ns & $\mathrm{ns}$ & $\mathrm{ns}$ & $\mathrm{ns}$ \\
\hline $\mathrm{CV}(\%)$ & 3,46 & 3,21 & 4,55 & 4,44 & 4,32 & 4,51 \\
\hline
\end{tabular}

$\mathrm{L}=$ efeito linear; $\mathrm{Q}=$ efeito quadrático; ${ }^{*} \mathrm{P} \leq 0,05 ;{ }^{* *} \mathrm{P} \leq 0,01 ;{ }^{* *} \mathrm{P} \leq 0,001$. 
a resistência óssea das aves. A suplementação de fitase (300 a 1.200 UF) em rações com baixo nível de fósforo disponível melhora a resistência óssea das aves.

\section{Literatura Citada}

BARKLEY, G.R.; MILLER, H.M.; FORBES, J.M. The ability of laying hens to regulate phosphorus intake when offered two feeds containing different levels of phosphorus. British Journal of Nutrition, v.92, p.233-240, 2004.

BOLING, S.D.; DOUGLAS, M.W.; JOHNSON, M.L. et al. The effects of dietary available phosphorus levels and phytase on performance of young and older laying hens. Poultry Science, v.79, p.224-225, 2000.

BORGES, F.M.O. Utilização de enzimas em dietas avícolas. Cadernos Técnicos da Escola de Veterinária da UFMG, n.20, p.1053-1057, 1997.

BORRMANN, M.S.L.; BERTECHINI, A.G.; FIALHO, E.T. et al. Efeitos da adição de fitase com diferentes níveis de fósforo disponível em rações de poedeiras de segundo ciclo. Revista Ciência Agrotécnica, v.25, n.1, p.181-187, 2001.

CASARTELLI, E.M.; JUNQUEIRA, O.M.; LAURENTIZ, A.C. et al. Effect of phytase in laying hen diets with different phosphorus sources. Brazilian Journal of Poultry Science, v.7, p.93-96, 2005.

CONTE, A.J.; TEIXEIRA, A.S.; FIALHO, E.T. et al. Efeito da fitase e xilanase sobre o desempenho e as características ósseas de frangos de corte alimentados com dietas contendo farelo de arroz. Revista Brasileira de Zootecnia, v.32, n.5, p.1147-1156, 2003.

CONTE, A.J.; TEIXEIRA, A.S.; FIGUEIRÊDO, A.V. et al. Efeito da fitase na disponibilidade do fósforo do farelo de arroz em frangos de corte. Pesquisa Agropecuária Brasileira, v.37, n.4, p.547-552, 2002.

COSTA, F.G.P.; JACOME, I.M.T.D.; SILVA, J.H.V. Níveis de fósforo disponível e de fitase na dieta de poedeiras de ovos de casca marrom. Ciência Animal Brasileira, v.5, n.2, p.73-81, 2004.

De LANGE, K.; NYACHOTI, M.; BIRKETT, S. Manipulation of diets to minimize the contribution to environmental pollution. Advances in Pork Production, v.10, p.173-186, 1999.
HEMPE, J.M.; LAUXEN, R.C.; SAGAGE, J.E. A rapid determination of egg weight and specific gravity using computerized collection system. Poultry Science, v.67, p.902-907, 1988.

KIES, A.; HEMERT, K.V.; SELLE, P. et al. The protein effect of phytase. In: BASF. Enzyme and organic acid in Dutch feed industry. London: 1997. p.1-7.

LIEBERT, F.; HTOO, J.K.; SÜNDER, A. Performance and nutrient utilization of laying hens fed low-phosphorus corn-soybean and wheat soybean diets supplemented with microbial phytase. Poultry Science, v.84, p.1576-1583, 2005.

NATIONAL RESEARCH COUNCIL - NRC. Nutrient requirements of poultry. Washington, D.C.: National Academy Press, 1994. 156p.

ONYANGO, E.M.; HESTER, P.Y.; STROSHINE, R. et al. Bone densitometry as an indicator of percentage tibia ash in broiler chicks fed varying calcium and phosphorus levels. Poultry Science, v.82, p.1787-1791, 2003.

ROSTAGNO, H.S.; ALBINO, L.F.T.; DONZELE, J.L. et al. Tabelas brasileiras de exigências nutricionais para aves e suínos (Composição de alimentos e exigências nutricionais). 3.ed. Viçosa, MG: Universidade Federal de Vicosa, 2005. 141p.

ROWLAND, L.O.; HARMS, R.H.; WILSON, H.R. et al. Influence of various dietary factors on bone fragility of caged layers. Poultry Science, v.47, p.507-511, 1968.

SHIRLEY, R.B.; EDWARDS JR.; H.M. Graded levels of phytase past industry standard improves broiler performance. Poultry Science, v.82, p.671-680, 2003.

SILVA, D.J. Análises de alimentos (Métodos físicos e biológicos). Viçosa, MG: Universidade Federal de Viçosa, 1991. 166p.

VIEIRA, R.S.A.; BERTECHINI, A.G.; FIALHO, E.T. et al. Desempenho e qualidade de ovos de poedeiras comerciais de Segundo ciclo alimentadas com rações contendo fitase. Revista Ciência e Agrotecnologia, v.25, p.1413-1422, 2001.

WALDROUP, P.W.; KERSEY, J.H.; SALEH, E.A. et al. Nonphytate phosphorus requirement and phosphorus excretion of broiler chicks fed diets composed of normal or high available phosphate corn with and without microbial phytase. Poultry Science, v.79, p.1451-1459, 2000.

WU, G.; LIU, A.; BRYANT, M.M. et al. Comparison of natuphos and phyzyme as phytase sources for commercial layers fed corn-soy diet. Poultry Science, v.85, p.64-79, 2006.

YU, B.; JAN, Y.C.; CHUNG, T.K. et al. Exogenous phytase activity in the gastrointestinal tract of broiler chickens. Animal Feed Science and Tecnhnology, v.117, p.295-303, 2004. 